\title{
Thyroid Hormone Augments GLUT4 Expression and Insulin-Sensitive Glucose Transport System in Differentiating Rat Brown Adipocytes in Culture
}

\author{
Yasutake SHIMIZU ${ }^{1) *}$ and Takashi SHIMAZU ${ }^{1)}$ \\ ${ }^{1)}$ Department of Medical Biochemistry, Ehime University School of Medicine, Shigenobu, Ehime 791-0295, Japan
}

(Received 17 January 2002/Accepted 1 April 2002)

\begin{abstract}
The effects of triiodothyronine (T3) on differentiation-dependent expression of GLUT and responses of glucose transport to insulin and norepinephrine (NE) were investigated. Precursor cells of brown adipocytes isolated from the interscapular brown adipose tissue of newborn rats were cultured in the absence or presence of various concentrations of T3. Western bolt analysis revealed that treatment with T3 resulted in an increased expression of GLUT4, in a dose-dependent manner, whereas GLUT1 contents were unchanged. In parallel with the increase in GLUT4 expression, T3 improved insulin sensitivity for glucose transport, being accompanied by an increase in maximal transport rate and a reduction of $\mathrm{ED}_{50}$. In contrast, T3-treatment of the brown adipocytes during the differentiation process had little effect on NE-regulatable glucose transport system. These results suggest that T3 plays a predomina nt role in the development of insulin-sensitive glucose transport during differentiation of brown adipocytes.
\end{abstract}

KEY WORDS: GLUT, insulin, norepinephrine, rat brown adipocyte, T3.

J. Vet. Med. Sci. 64(8): 677-681, 2002

Brown adipose tissue (BAT) is a heat-generating organ that plays an important role in recovery from hibernation or hypothermia, and in maintaining body temperature in newborns and cold-exposed mammals [8, 13, 21]. BAT is also important for maintaining energy balance during spontaneous hyperphagia, as it is activated in response to diet [16]. Its thermogenic capacity is due to the presence of mitochondrial uncoupling protein (UCP) that short-circuits the proton gradient across the inner mitochondrial membrane, thus uncoupling fuel oxidation with ATP synthesis [13]. Although the principal substrate for BAT thermogenesis is considered to be fatty acids, glucose may also be an important fuel, not only as a carbon source for fatty acid synthesis but also as a precursor for sufficient supply of oxaloacetate, which is essential for rapid oxidation of fatty acids. In line with this, it has been shown that glucose utilization as well as expression of the GLUT4 glucose transporter in BAT are markedly enhanced under cold environment, independently of the action of insulin [14, 22, 26].

BAT thermogenesis is activated by norepinephrine (NE) released from sympathetic nerve endings [20], but it has an absolute requirement for thyroid hormone [28]. For instance, hypothyroid animals are intolerant to cold and even die when exposed to cold for several hours [1, 18]. These animals are accompanied with the reduction of basal and adrenergically stimulated UCP mRNA in BAT [27], indicating that thyroid hormones seem necessary for the full expression of UCP and thermogenic function in vivo. Recently, Hernandez and Obregon [7] clearly showed that triiodothyronine (T3) is required and potentiates the adrenergic activation of UCP expression during differentiation of rat brown preadipocytes into matured adipocytes in culture.

\footnotetext{
* Present address: Shimizu, Y., Department of Veterinary Physiology, Faculty of Agriculture, Gifu University, Gifu 501-1193, Japan.
}

The adipocyte differentiation is characterized by an increased lipogenic capacity and a change from a fibloblast morphology to the lipid-accumulated appearance $[6,12]$. The differentiation process is accompanied by the induction and increased expression of a number of specific molecules, including lipoprotein lipase, glycerol-3-phosphate dehydrogenase, and GLUT4 [6, 12]. The emergence of the insulinmediated glucose transport response is also a marker as the differentiation of adipocytes [12]. We previously demonstrated that GLUT4 expression is promoted during the differentiation period of brown adipocytes in primary culture, in parallel with induction of insulin- and NE-regulatable glucose transport activities [15, 23, 24]. In these experiments, T3 was included in the medium for the differentiation of cultured brown preadipocytes, but the precise role of T3 in GLUT4 expression has not been clarified in brown adipocytes. Thus, the aim of the present work is to establish its role in GLUT4 expression by using the primary cultures of rat brown adipocytes. In addition, we analyzed the effect of the hormone on the differentiation-dependent induction of two glucose transport systems, one of which responds to insulin and the other to NE.

\section{MATERIALS AND METHODS}

Materials: 2-Deoxy-D- $\left[{ }^{3} \mathrm{H}\right] \mathrm{glucose}(2-\mathrm{DG})$ and $\left[{ }^{14} \mathrm{C}\right]$ sucrose were obtained from American Radiolabeled Chemicals (St. Louis, MO, U.S.A). $\left[{ }^{125}\right.$ I]Protein A was from ICN Radiochemicals (Costa Mesa, CA, U.S.A). Insulin, NE, dexamethasone, T3, collagenase (type I), and BSA were from Sigma (St. Louis, MO, U.S.A). Dulbecco's modified Eagle's medium (DMEM) was from Nissui Pharmaceutical Co., Ltd (Tokyo, Japan). Fetal calf serum (FCS) was from Whittaker Bioproducts Inc (Verviers, Belgium). Antisera against C-terminal peptides of GLUT4 or GLUT1 
were prepared as previously described [26].

Cell isolation and culture. Brown fat precursor cells were isolated as the stromal-vascular fraction from the interscapular brown fat of newborn rats by the procedure described previously [24]. Cells isolated by collagenase digestion were suspended in DMEM supplemented with $10 \%$ FCS, 17 $\mu \mathrm{M}$ D-pantothenic acid, $33 \mu \mathrm{M}$ d-biotin, $100 \mu \mathrm{M}$ ascorbic acid, $1 \mu \mathrm{M}$ octanoic acid, 100 units $/ \mathrm{m} l$ penicillin, $0.1 \mathrm{mg} / \mathrm{m} l$ streptomycin, and $50 \mathrm{nM}$ insulin, and were seeded on collagen-coated dishes. The cells were incubated at $37^{\circ} \mathrm{C}$ under an atmosphere of $5 \% \mathrm{CO}_{2}$ in air. When the cultured cells reached confluence, they were treated with $1 \mu \mathrm{M}$ dexamethasone for $48 \mathrm{hr}$ [24]. The cells were used 3-4 days after reaching confluence. T3 was added to some dishes at the final concentration of $0.01,1$, or $100 \mathrm{nM}$ from the second day after plating.

Glucose transport measurements: 2-DG transport was measured with differentiated brown adipocytes [23]. Cells seeded in 35-mm dishes were washed three times with HEPES-buffered saline solution $(140 \mathrm{mM} \mathrm{NaCl}, 1 \mathrm{mM}$ $\mathrm{CaCl}_{2}, 5 \mathrm{mM} \mathrm{KCl}, 2.5 \mathrm{mM} \mathrm{MgSO}_{4}$, and $20 \mathrm{mM}$ HEPES, $\mathrm{pH}$ 7.4) and then pre-incubated with plain DMEM for $3 \mathrm{hr}$ at $37^{\circ} \mathrm{C}$, to reduce the effects of serum and supplements including T3. Where indicated, insulin or NE was added during the last $1 \mathrm{hr}$ of the pre-incubation. Then the cells were rinsed twice with the HEPES-buffered saline solution. After incubation for 20 min with the HEPES-buffered saline containing $2 \%$ fatty acid-free BSA in the presence or absence of insulin (or NE), the cells were further incubated with $50 \mu \mathrm{M} 2$-deoxy-D-[ $\left.{ }^{3} \mathrm{H}\right]$ glucose $(0.01 \mu \mathrm{Ci} / \mathrm{nmol})$ in the same solution. 2-DG transport was allowed to proceed for 2 min, and was terminated by rapid suction and subsequent washing with ice-cold $3 \mathrm{mM} \mathrm{HgCl} 2$ in phosphate-buffered saline (PBS). Contamination of the isotope due to extracellular space was corrected using $\left[{ }^{14} \mathrm{C}\right]$ sucrose. The net transport of 2-DG was expressed in $\mathrm{pmol} / \mathrm{min} / \mathrm{mg}$ protein $\pm \mathrm{SE}$.

Western blot analysis: Differentiated brown adipocytes grown in 60-mm dishes were rinsed 3 times with PBS, and then scraped from the dishes with a plastic cell scraper. The cells were sedimented by low-speed centrifugation and were hypotonically lysed in a buffer containing $1 \mathrm{mM} \mathrm{NaHCO}_{3}$, $0.5 \mathrm{mM} \mathrm{CaCl}_{2}$, and $0.2 \mathrm{mM} \mathrm{MgSO}_{4}\left(\mathrm{pH} \mathrm{7.4)}\right.$ at $4{ }^{\circ} \mathrm{C}$. Following sonication of the cell lysates, the materials were centrifuged at $1,500 \times \mathrm{g}$ for $10 \mathrm{~min}$. GLUT4 or GLUT1 content of the resulting supernatant was determined by Western blot analysis, using rabbit antiserum against $\mathrm{C}$-terminal peptide of GLUT4 or GLUT1 and ${ }^{125}$ I-labeled protein A. Immunoreactivity was analyzed with BAS-1000 (Fuji Film, Tokyo, Japan). In each blotting, tissue homogenate of the BAT (for GLUT4) or human erythrocyte ghost (for GLUT1) was subjected to run and its immuno-reactivity was used for standardization.

Statistical analysis: All values were presented as means \pm SE. Statistical significance was examined by analysis of variance (ANOVA). Comparisons between groups were made by Student's $t$-test.

\section{RESULTS}

Effects of T3 on the GLUT4 and GLUT1 expression during differentiation of cultured brown adipocytes: The expression of GLUT4 during differentiation of the precursor cells into matured brown adipocytes in the absence or presence of three different concentrations of T3 were examined by Western blotting. As shown in Fig. 1, GLUT4 was detected even when T3 was not supplemented to the differentiation medium. However, addition of T3 in the medium potentiated GLUT4 expression in a dose-dependent manner. GLUT4 immuno-reactivities of the cells treated with 0.01 , 1 , and $100 \mathrm{nM}$ T3 were $122 \pm 11,198 \pm 26$ and $223 \pm 27 \%$ of untreated cells, respectively. In contrast to GLUT4, treatment with varying concentrations of T3 did not change GLUT1 contents (Fig. 1).

Effects of T3 treatment on the responses of glucose transport to insulin and NE in cultured brown adipocytes. Figure 2 shows dose-response curves for the action of insulin on glucose transport activity by cultured brown adipocyes. The transport activity was measured using the non-metabolizable glucose analog 2-DG, and expressed mean \pm SE of five independent experiments, each of which composed duplicate or triplicate assays. Both in T3 $(100 \mathrm{nM})$-treated and untreated cells, insulin increased glucose transport progressively at concentrations from $10^{-11}$ to $10^{-6} \mathrm{M}$ with a maximal stimulation at $10^{-7} \mathrm{M}$. A two-way ANOVA indicated that, in addition to significant effects of $\mathrm{T} 3$ treatment $[F(1,8)=$ $82.3, P<0.001]$ and concentration of insulin $[F(6,48)=59.7$, $P<0.001]$, there was a significant effect of a treatment by concentration interaction $[F(6,48)=17.9, P<0.001]$. Maximal transport rate was about 4 -fold in T3-treated cells whereas 2-fold in T3-untreated cells, as compared with respective basal transport rate, which is higher in T3-treated

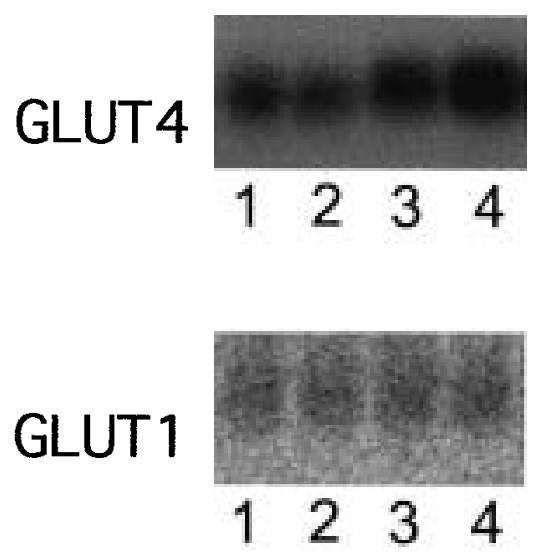

Fig. 1. Effects of T3 on the GLUT4 and GLUT1 expression during differentiation of cultured brown adipocyte. The rat brown adipocytes were cultured in the absence (lane 1) or presence of $0.01,1$ and $100 \mathrm{nM}$ of T3 (lanes 2-4, respectively). The cells were homogenized and $10 \mu \mathrm{g}$ and $20 \mu \mathrm{g}$ of the samples were subjected to Western blot analysis for GLUT4 and GLUT1, respectively. Similar reproducible results were obtained in five independent experiments. 


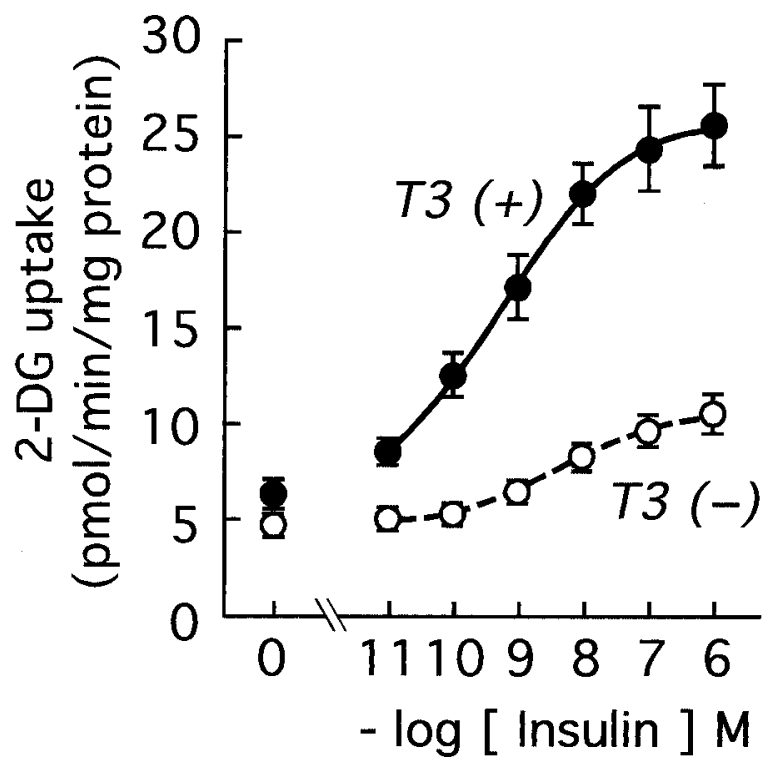

Fig. 2. Dose-response curves for insulin as to 2-DG uptake by cultured brown adipocytes. The rat brown adipocytes were cultured in the absence (T3(-)) or presence of $100 \mathrm{nM}$ of T3 $(\mathrm{T} 3(+))$. Before measuring 2-DG uptake, cells were pre-incubated with plain DMEM for $3 \mathrm{hr}$ at $37^{\circ} \mathrm{C}$, to reduce the effects of serum and supplements including T3. Insulin was added during the last $1 \mathrm{hr}$ of pre-incubation, and then 2-DG uptake was measured as described under "Materials and Methods". Values are means $\pm \operatorname{SE}(\mathrm{n}=5)$.

cells than in T3-untreated cells. The calculated $\mathrm{ED}_{50}$ value was $1.4 \pm 0.6 \mathrm{nM}$ for T3-treated cells, which is significantly lower than that for T3-untreated cells $(5.2 \pm 3.2 \mathrm{nM})$ $(P<0.05)$.

The effect of T3 treatment on NE-regulatable glucose transport was also examined. As shown in Fig. 3, stimulation with NE enhanced the rate of glucose transport in a dose-dependent manner both in T3-treated and -untreated cells. A two-way ANOVA showed a significant effect of T3 treatment $[F(1,8)=69.5, P<0.001]$ and concentration of $\mathrm{NE}$ $[F(6,48)=170.4, P<0.001]$, as well as a significant interaction $[F(6,48)=5.85, P<0.001]$. Although the net maximal transport rate was significantly higher in T3-treated cells (12.4 $\mathrm{pmol} / \mathrm{min} / \mathrm{mg}$ protein) than in T3-untreated cells (8.9 $\mathrm{pmol} / \mathrm{min} / \mathrm{mg}$ protein), the fold-increment was comparable as about 2-fold. T3 treatment did not significantly influence the $\mathrm{ED}_{50}$ values; $3.8 \pm 0.9 \mathrm{nM}$ for T3-treated cells and $3.2 \pm$ $0.9 \mathrm{nM}$ for T3-untreated cells.

\section{DISCUSSION}

We have previously demonstrated that treatment of precursor cells of rat brown adipocytes with dexamethasone promotes GLUT4 expression in parallel with the responses of glucose transport to insulin and NE [15, 23, 24]. Shima et al. also showed the essential role of dexamethasone in dif-

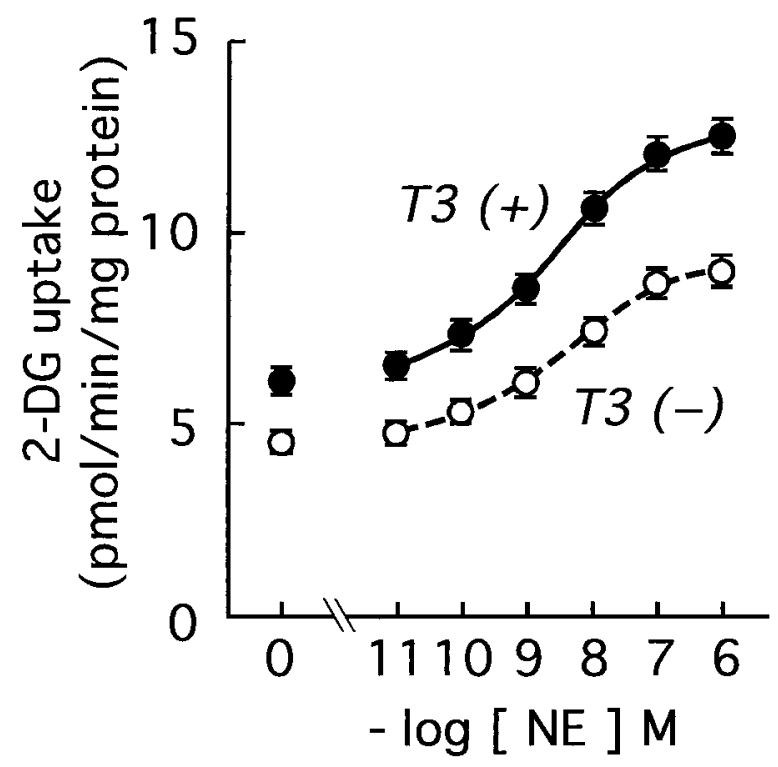

Fig. 3. Dose-response curves for NE as to 2-DG uptake by cultured brown adipocytes. The rat brown adipocytes were cultured in the absence (T3(-)) or presence of $100 \mathrm{nM}$ of T3 $(\mathrm{T} 3(+))$, and 2-DG uptake was measured as in the legend to Fig. 2. Values are means $\pm \operatorname{SE}(n=5)$.

ferentiation-dependent induction of GLUT4 mRNA in cultured brown adipocytes [19]. In these studies, thyroid hormone was always supplemented to culture medium as a benefical factor for the differentiation of cultured brown preadipocytes, and thus the precise role of the hormone in GLUT4 expression and development of glucose transport system has not so far fully been understood. In the present study, we examined the effects of T3 on differentiationdependent expression of GLUT and the responses of glucose transport to insulin and NE. Our results show that T3 dose-dependently potentiates GLUT4 expression and improves insulin sensitivity for glucose transport during differentiation process.

It has already been shown that cold exposure, which promotes hyperplasia and enhances thermogenic capacity of BAT [8], increases GLUT4 expression in BAT in vivo [14, 26]. Under the cold environment, in BAT, the type II 5'deiodinase is activated, leading to conversion of T4 to T3 and saturation of nuclear T3 receptors $[1,2,29]$. Thus, the potentiation of GLUT4 expression by T3 in the cultured cells seems compatible with the phenomenon observed in BAT in vivo. However, cold-induced GLUT4 expression in vivo requires an intact sympathetic innervation or the presence of NE infused exogenously [26, 32]. In the present study with cultured brown adipocytes, T3 was shown to potentiate GLUT4 expression without supplementation of NE. This apparent discrepancy between the in vivo and culture systems could be reconciled by supposing that adrenergic facilitation of GLUT4 expression in BAT is mediated, at least in part, by direct action of T3. Indeed, it has been dem- 
onstrated that the cold-induced activation of type II 5'-deiodinase is mediated by sympathetic nerve (or NE) [29]. In surgically dennervated BAT, the enzyme is not activated any more, which remains low $\mathrm{T} 3$ production and low receptor occupancy, and thus GLUT4 expression may not be stimulated.

Expression of GLUT4 is one of the typical markers for the differentiation of adipocytes [12]. In accordance with this, we have previously demonstrated that GLUT4 was not detected in the precursor cells of brown adipocytes, but its expression was induced by dexamethasone in parallel with notable accumulation of lipid droplets [24]. In the present study GLUT4 was expressed in cultured brown adipocytes even when T3 was not supplemented to the differentiation medium (Fig. 1). This indicates that T3 is not an obligatory factor but a positive modulator for brown adipocyte differentiation at least in the culture system.

We observed that T3 increased the basal rate of glucose transport in cultured brown adipocytes (Figs. 2 and 3). It has been reported that $\mathrm{T} 3$ itself increases glucose transport in some types of cells, including muscle cells, heart cells, hepatocytes, thymocytes and mononuclear blood cells [4, $10,11,17,34]$. Although it is generally considered that basal uptake of glucose in insulin-sensitive tissues including BAT is mediated by GLUT1 [5], GLUT1 contents were unaltered by treatment of T3 (Fig. 1). Considering that GLUT1 activity can be modified in the plasma membrane without changes in the protein level $[3,9,25]$, it is possible that T3 increases an intrinsic activity of GLUT1. Alternatively, increased GLUT4 contents would be attributable to the increase in basal uptake of glucose. Further studies, such as cell surface labeling of GLUT, are needed to clarify the mechanism of T3-induced increase in basal glucose uptake.

The present study indicates that $\mathrm{T} 3$ treatment of brown adipocytes during differentiation improves insulin sensitivity for glucose transport (Fig. 2). This was accompanied by an increase in maximal transport rate and a reduction of $\mathrm{ED}_{50}$. Similar improvement of insulin sensitivity as well as GLUT4 expression by T3 has also been observed in skeletal muscle [34], indicating that such effects of T3 are not unique to brown adipocytes. The mechanism by which insulin enhances glucose transport in adipocytes and muscle cells has been well established to be due to the translocation of GLUT4 from an intracellular pool to the plasma membrane $[3,5,9]$. It seems, therefore, most likely that the increased GLUT4 contents account for the improved sensitivity of glucose transport to insulin. In accordance with this, it has been reported that the increased GLUT4 expression in BAT under cold environment is associated with potentiation of the insulin effect on glucose uptake in vivo [33].

We have previously demonstrated that glucose transport in brown adipocytes is also activated by NE, independently of the action of insulin $[22,23,25,30,31]$. We thus examined the effects of T3 treatment on NE-induced glucose transport. T3-treated cells showed higher rates of glucose transport at any concentrations of NE as compared with untreated cells, probably due to the increase in basal transport (Fig. 3). This indicates that T3 dose not influence the NE-regulatable glucose transport during differentiation of brown adipocytes. In fact, $\mathrm{ED}_{50}$ value for $\mathrm{NE}$ was not changed by the treatment with $\mathrm{T} 3$.

In summary, the present results demonstrate that treatment with T3 during differentiation of brown adipocytes improves the insulin sensitivity for glucose transport, in parallel with an increase in GLUT4 expression. The fact that these T3-induced changes in the cultured cells well correspond with the reactions of BAT after cold exposure in rats, indicates a predominant role of $\mathrm{T} 3$ in functional activation of brown adipocytes.

\section{REFERENCES}

1. Bianco, A. C. and Silva, J. E. 1987. Intracellular conversion of thyroxine to triiodothyronine is required for the optimal thermogenic function of brown adipose tissue. J. Clin. Invest. 79: 295-300.

2. Bianco, A. C. and Silva, J. E. 1988. Cold exposure rapidly induces virtual saturation of brown adipose tissue nuclear T3 receptors. Am. J. Physiol. 255: E496-E503.

3. Czech, M. P., Clancy, B. M., Pessino, A., Woon, C. W. and Harrison, S. A. 1992. Complex regulation of simple sugar transport in insulin-responsive cells. Trends Biochem. Sci. 17: 197-201.

4. Gordon, A., Schwartz, H. and Gross, J. 1986. The stimulation of sugar transport in heart cells grown in a serum-free medium by picomolar concentrations of thyroid hormones: the effects of insulin and hydrocortisone. Endocrinology 118: 52-57.

5. Gould, G. W. and Holman, G. D. 1993. The glucose transporter family: structure, function and tissue-specific expression. Biochem. J. 295: 329-341.

6. Hausman, G. J., Campion, D. R. and Martin, R. J.1980. Search for the adipocyte precursor cell and factors that promote its differentiation. J. Lipid Res. 21: 657-670.

7. Hernandez, A. and Obregon, M. J. 2000. Triiodothyronine amplifies the adrenergic stimulation of uncoupling protein expression in rat brown adipocytes. Am. J. Physiol. 278: E769E777.

8. Himms-Hagen, J. 1986. Brown adipose tissue and cold-acclimation. pp. 214-268. In: Brown Adipose Tissue (Trayhurn, P. and Nicholls, D. G. eds), Edward Arnold, London.

9. Ismail-Beigi, F. 1993. Metabolic regulation of glucose transport. J. Membrane Biol. 135: 1-10.

10. Kuruvilla, A. K., Perez, C., Ismail-Beigi, F. and Loeb, J. N. 1991. Regulation of glucose transport in Clone 9 cells by thyroid hormone. Biochim. Biophys. Acta 1094: 300-308.

11. Kvetny, J. and Matzen, L. E. 1989. Thyroid hormone induced oxygen consumption and glucose-uptake in human mononuclear cells. Thyroidology 1: 5-9.

12. MacDougald, O. A. and Lane, M. D. 1995. Transcriptional regulation of gene expression during adipocyte differentiation. Annu. Rev. Biochem. 64: 345-373.

13. Nicholls, D. and Locke, R. 1984. Thremogenic mechanism in brown fat. Physiol. Rev. 64: 1-64.

14. Nikami, H., Shimizu, Y., Endoh, D., Yano, H. and Saito, M. 1992. Cold exposure increases glucose utilization and glucose transporter expression in brown adipose tissue. Biochem. Bio- 
phys. Res. Commun. 185: 1078-1082.

15. Nikami, H., Shimizu, Y., Sumida, M., Minokoshi, Y., Yoshida, T., Saito, M. and Shimazu, T. 1996. Expression of beta3adrenoceptor and stimulation of glucose transport by beta3agonists in brown adipocyte primary culture. J. Biochem. 119: 120-125.

16. Rothwell, N. J. and Stock, M. J. 1986. Brown adipose tissue and diet-induced thermogenesis. pp. 269-298. In: Brown Adipose Tissue (Trayhurn, P. and Nicholls, D. G. eds), Edward Arnold, London.

17. Segal, J. and Ingbar, S. H. 1990. 3,5,3'-tri-iodothyronine enhances sugar transport in rat thymocytes by increasing the intrinsic activity of the plasma membrane sugar transporter. $J$. Endocrinol. 124: 133-140.

18. Sellers, E. A. and You, S. S. 1950. Role of the thyroid in metabolic responses to a cold enviornment. Am. J. Physiol. 163: 8191.

19. Shima, A., Shinohara, Y., Doi, K. and Terada, H. 1994. Normal differentiation of rat brown adipocytes in primary culture judged by their expressions of uncoupling protein and the physiological isoform of glucose transporter. Biochim. Biophys. Acta 1223: 1-8.

20. Shimazu, T. 1986. Neuronal control of intermediate mabolism pp. 304-330. In: Neuroendocrinology (Lightman, S. L. and Everitt, B. J. eds), Blackwell Scientific Publications, Oxford

21. Shimizu, Y. and Saito, M. 1991. Activation of brown adipose tissue thermogenesis in recovery from anesthetic hypothermia in rats. Am. J. Physiol. 261: R301-R304.

22. Shimizu, Y., Nikami, H. and Saito, M. 1991. Sympathetic activation of glucose utillization in brown adipose tissue in rats. $J$. Biochem. 110: 688-692.

23. Shimizu, Y., Kielar, D., Minokoshi, Y. and Shimazu, T. 1996. Noradrenaline increases glucose transport into brown adipocytes in culture by a mechanism different from that of insulin. Biochem. J. 314: 485-490.

24. Shimizu, Y., Kielar, D., Masuno, H., Minokoshi, Y. and Shimazu, T. 1994. Dexamethasone induces the GLUT4 glucose transporter, and responses of glucose transport to norepinephrine and insulin in primary cultures of brown adipocytes. $J$.
Biochem. 115: 1069-1074.

25. Shimizu, Y., Satoh, S., Yano, H., Minokoshi, Y., Cushman, S. W. and Shimazu, T. 1998. Effects of noradrenaline on the cellsurface glucose transporters in cultured brown adipocytes: novel mechanism for selective activation of GLUT1 glucose transporters. Biochem. J. 330: 397-403.

26. Shimizu, Y., Nikami, H., Tsukazaki, K., Machado, U. F., Yano, H., Seino, Y. and Saito, M. 1993. Increased expression of glucose transporter GLUT-4 in brown adipose tissue of fasted rats after cold exposure. Am. J. Physiol. 264: E890E895.

27. Silva, J. E. 1988. Full expression of uncoupling protein gene requires the concurrence of norepinephrine and triiodothyronine. Mol. Endocrinol. 2: 706-713.

28. Silva, J. E. 2001. The multiple contributions of thyroid hormone to heat production. J. Clin. Invest. 108: 35-37.

29. Silva, J. E. and Larsen, P. R. 1983. Adrenergic activation of triiodothyronine production in brown adipose tissue. Nature (Lond.) 305: 712-713.

30. Sudo, M., Minokoshi, Y. and Shimazu, T. 1991. Ventromedial hypothalamic stimulation enhances peripheral glucose uptake in anesthetized rats. Am. J. Physiol. 261: E298-E303.

31. Takahashi, A., Sudo, M., Minokoshi, Y. and Shimazu, T. 1992. Effects of ventromedial hypothalamic stimulation on glucose transport system in rats tissues. Am. J. Physiol. 263: R1228R1234.

32. Tsukazaki, K., Nikami, H., Shimizu, Y., Kawada, T., Yoshida, T. and Saito, M. 1995. Chronic administration of beta-adrenergic agonists can mimic the stimulative effect of cold exposure on protein synthesis in rat brown adipose tissue. J. Biochem. 117: $96-100$

33. Vallerand, A. L., Perusse, F. and Bukowiecki, L. J. 1987. Cold exposure potentiates the effect of insulin on in vivo glucose uptake. Am. J. Physiol. 253: E179-E186.

34. Weinstein, S. P., O’Boyle, E. and Haber, R. S. 1994. Thyroid hormone increases basal and insulin-stimulated glucose transport in skeletal muscle. The role of GLUT4 glucose transporter expression. Diabetes 43: 1185-1189. 